\title{
Distal Interphalangeal Joint 2 of the Foot
}

National Cancer Institute

\section{Source}

National Cancer Institute. Distal Interphalangeal Joint 2 of the Foot. NCI Thesaurus. Code C114198.

A ginglymoid (hinge) synovial joint within the second digit of the foot connecting the middle and distal phalanges. 